\title{
Long-Acting Moxidectin for the Control of Gastrointestinal Nematodes in Preweaned Beef Calves in Tropical Areas
}

Guilherme Henrique Reckzigel

Faculdade de Medicina Veterinária e Zootecnia, Universidade Federal de Mato Grosso do Sul

Av. Sen. Filinto Müler, 2443, Campo Grande-MS, Brazil

Phone: 55-67-99217-3453Ｅmail: ghreckziegel@gmail.com

Mario Henrique Conde

Faculdade de Medicina Veterinária e Zootecnia, Universidade Federal de Mato Grosso do Sul

Av. Sen. Filinto Müler, 2443, Campo Grande-MS, Brazil

Mariana Green de Freitas

Faculdade de Medicina Veterinária e Zootecnia, Universidade Federal de Mato Grosso do Sul

Av. Sen. Filinto Müler, 2443, Campo Grande-MS, Brazil

Matheus Takemi Muchon Nakatani

Faculdade de Medicina Veterinária e Zootecnia, Universidade Federal de Mato Grosso do Sul

Av. Sen. Filinto Müler, 2443, Campo Grande-MS, Brazil

Dyego Gonçalves Lino Borges

Faculdade de Medicina Veterinária e Zootecnia, Universidade Federal de Mato Grosso do Sul

Av. Sen. Filinto Müler, 2443, Campo Grande-MS, Brazil 
Elio Moro

Zoetis Animal Health

Henri Dunant Street, 1383, Morumbi Corporate, São Paulo, SP CEP 04709-111, Brazil

Fernando de Almeida Borges (Corresponding Author)

Faculdade de Medicina Veterinária e Zootecnia, Universidade Federal de Mato Grosso do Sul

Av. Sen. Filinto Müler, 2443, Campo Grande-MS, Brazil

Received: August 5, 2021 Accepted: October 6, $2021 \quad$ Published: October 9, 2021

doi:10.5296/jas.v9i4.18910 URL: https://doi.org/10.5296/jas.v9i4.18910

\begin{abstract}
Gastrointestinal nematodes (GINs) in beef calves in the preweaning period can be an underestimated problem, and an adequate control program can result in increased productivity. In the current scenario of anthelmintic resistance, clinical studies with highly effective molecules with a prolonged period of action can contribute to the development of technologies applied in the field. The objective of this study was to evaluate the effects of a $10 \%$ moxidectin formulation $(10 \% \mathrm{MOX})$, administered to calves aged 4-5 months, in the control of gastrointestinal nematodes and weight gain until the time of weaning. The study was divided into 2 stages. The first stage was carried out on a farm, with a randomized block design based on fecal egg counts (FEC), live weight, number of calvings of the mother, breed of the calves, and pickets. In the second stage, the study was repeated on 10 other farms, following a completely randomized design, to confirm the results obtained in the first stage. In all experiments there was a treated group and a placebo group. In the first stage, the effectiveness of $10 \% \mathrm{MOX}$ in the FECRT performed on the $38^{\text {th }}$ day post-treatment was $98.49 \%$, and the treated animals still had lower FEC averages and a $9.4 \mathrm{~kg}$ increase in weight at weaning compared to those from the placebo group. In the second stage, the average increase in weight gain was $6.1 \mathrm{~kg}$, confirming the results of the first stage. The study demonstrated effective control of GINs and improvement in the productive performance of calves treated in the preweaning phase, using $10 \%$ moxidectin.
\end{abstract}

Keywords: cattle, gastrointestinal nematodes, weight gain, control

\title{
1. Introduction
}

Gastrointestinal nematodes (GINs) are among the biggest causes of economic loss in beef cattle farming worldwide, due to their direct action and also the expenses generated with control attempts (Knox et al., 2012; Van Der Voort et al., 2013; Grisi et al., 2014). In Brazil, 
GINs incur an annual economic impact of approximately US\$7.11 billion, taking into account only the reduction in the productive performance of affected animals (Grisi et al., 2014).

The strategic control of GINs in weaned stocker beef calves in Central Brazil currently consists of treating animals from weaning up to 18-24 months of age. This is considered the animal category with higher susceptibility to GINs, and it consequently represents a higher financial loss (Bianchin et al., 1996). Heckler et al. (2016) evaluated the effects of anthelmintic treatment in animals in the growing phase, concluding that animals that were treated 3 times a year, even when the effectiveness of the drug used was below the recommended, obtained greater weight gain than animals that were treated twice or not at all. This strategic control scheme resulted in an economic return of US $\$ 14.3$ to US $\$ 49.96$, depending on the economic scenario and the productivity obtained (Conde et al., 2019). Weight gain in the growing phase of treated animals was also observed in studies carried out in the United States (Walker et al., 2013) and in Argentina (Suarez et al., 2016).

Initially, verminosis in calves in the preweaning period was not considered of great importance, and it was believed that through the treatment of cows in the pre-calving period, there would be an effect on the control of parasitism in calves, because the cows were considered the sources of contamination of the pastures. On this basis, the treatment of calves was not recommended (Bianchin et al., 1987). However, a more recent study carried out with beef cattle in Brazil showed that fecal worm egg count (FEC) per gram in the preweaning category was higher than in other categories, making this category more vulnerable to infection by GINs (Martins, 2018).

Under tropical conditions, the treatment of preweaning calves and cows during the suckling period was evaluated by Catto et al. (2005), who did not observe any effect of the treatment of cows on the weight of the calves; however, the calves treated at 4-5 months of age showed greater weight gain. In this study, ivermectin (IVM) was used, and the effect of a conventional formulation was also compared to that of a long-acting (IVM-LA) agent, noting that only IVM-LA resulted in an average increase in weight gain in calves of $7.1 \mathrm{~kg}$ compared to the control group. A similar result was obtained with IVM-LA in calves at 4-6 months, but under different epidemiological conditions, with gains of 22.7 and $12.4 \mathrm{~kg}$ in the period of 84-100 days of evaluation (Rehbein et al., 2016).

In these two studies, an increase in weight gain in calves treated with IVM-LA at 4-6 months was proven, with high efficacy greater than $94 \%$ up to the $70^{\text {th }}$ DPT. However, in Brazil and other countries, IVM, even at higher concentrations, is no longer showing satisfactory efficacy due to the phenomenon of resistance (Borges et al., 2015), while moxidectin (MOX) may still be effective against these ivermectin-resistant populations (Soutello et al., 2007, Fazzio et al., 2014). A study in Argentina clearly shows the advantage of MOX treatment in calves infected by a population of ivermectin-resistant GINs, with weight gains of $15.7 \mathrm{~kg}$ and $23.5 \mathrm{~kg}$ in calves treated with IVM and MOX, respectively (Canton et al., 2020).

The aim of this study was to evaluate the effects of $10 \%$ moxidectin formulation on the control of gastrointestinal nematodes and on the performance of calves treated in the preweaning period. 


\section{Method}

This study was carried out on 11 commercial farms dedicated to the production of beef cattle, and divided into 2 stages. The first stage was developed in a randomized block design based on fecal worm egg count (FEC) per gram, live weight, number of calvings of the dam, breed of calves, and pickets. In the second stage, the study was repeated in 10 different locations, in different Brazilian states, following a completely randomized design, to confirm the results obtained in the first stage.

\subsection{First Stage}

\subsubsection{Location and Animals}

In a farm located in the city of Bela Vista, state of Mato Grosso do Sul, Brazil, 202 animals aged between 3 and 5 months, fixed-time artificial insemination products, and offspring of multiparous Nellore cows were used, with the latter having been mated with bulls of the Nellore and Angus breeds, all evenly distributed between treatments. The study animals were kept together with their mothers.

\subsubsection{Pickets}

Five area repetitions, called Pickets 12, 15, 21, FP, and LA, were used. Pickets 12, 15, 21, and LA were formed by Brachiaria brizantha cv. Marandu, and the FP picket by Brachiaria humidicola cv. Llanero. All animals received mineralized salt and fresh water ad libitum.

\subsubsection{Treatment}

The 202 animals were divided into 2 groups according to a randomized block design, considering the FEC factors, weight, breed, and number of calvings of the dam and bull, in each of the 5 area repetitions. Treatments were randomly assigned within each block: Treatment 1: Moxidectin 10\% (10\%MOX), $1,000 \mu \mathrm{g} / \mathrm{kg}$, in a single dose injected subcutaneously at the base of the right ear, as recommended by the manufacturer; Treatment 2: Placebo (saline solution- $0.9 \% \mathrm{NaCl}$ - injected subcutaneously in the injection triangle).

Treatment was carried out on day D0, after allocation of the animals to the groups according to the randomization plan.

\subsubsection{FEC Counts, Coproculture, and Weight Gain Assessment}

Parasitism by GINs was assessed on the day of treatment (D0) and on the day of weaning of the animals (D120), which was performed in stages according to the age of the animals. Individual stool samples were collected directly from the rectal ampoule, transported under refrigeration to the Laboratory of Parasitic Diseases/FAMEZ/UFMS for FEC counts using the modified Gordon \& Whitlock (1939) technique, with 1:25 sensitivity. Pools per group were made from these same samples for stool cultures to determine the genera of nematodes present (Roberts \& O'Sullivan, 1950). Stool cultures were performed in triplicate in each of the 5 area replicates to determine the nematode genders present in the animals participating in the study. To identify the $3^{\text {rd }}$ instar larvae (stage) (L3), the taxonomic criteria described by Keith (1953) and Ueno and Gonçalves (1998) were used. A pool of fecal samples from the 
animals collected on days zero, on D38, and on the weaning date was made for each group in each repetition area.

To assess the efficacy of $10 \% \mathrm{MOX}$, a fecal egg count reduction test (FECRT) was performed on the $38^{\text {th }}$ day after treatment according to Coles et al. (1992). For this, tests were performed in 2 replicates of each area, with 24 and 59 animals selected from each area. The effectiveness was calculated using the following mathematical equation: Efficacy $(\%)=$ [1-(T2/C2)]x100, where T2: mean FEC of the treated group in the posttreatment sampling and C2: mean FEC of the control group in the posttreatment sampling. Lower and upper limits of efficacy at the $95 \%$ confidence interval were also calculated.

Weight gain was evaluated by weighing the animals individually on the day of treatment (D0) and on the weaning days (D120), calculating the average weight gain and the average daily gain.

\subsection{Second Stage}

Another 10 clinical studies were carried out on commercial farms distributed in 4 different geographic regions of Brazil (Table 1), where 686 calves were randomly distributed between the groups treated with $10 \% \mathrm{MOX}$ and the placebo group, with application of saline solution.

Table 1. Geographic location of farms, number of animals in each group, and animal characteristics in clinical studies evaluating the weight gain of calves treated with $10 \% \mathrm{MOX}$ in the preweaning period

\begin{tabular}{lllcc}
\hline State/Region & Age & Sex & $\begin{array}{c}\text { Number } \\
\text { placebo } \\
\text { animals }\end{array}$ & $\begin{array}{c}\text { of } \\
\text { Number } \\
\text { animals } \\
\text { treated }\end{array}$ \\
\hline Goiás/Midwest & NI & M/F & 52 & 63 \\
Mato Grosso/Midwest & 4 months & M/F & 45 & 46 \\
Mato Grosso/Midwest & $4-5$ months & M & 3 & 28 \\
Minas Gerais/Southeast & $3-4$ months & NI & 19 & 23 \\
Minas Gerais/Southeast & $6-8$ months & NI & 41 & 40 \\
Pará/North & $4-5$ months & M & 56 & 55 \\
Rio Grande do Sul/South & NI & M & 21 & 24 \\
São Paulo/Southeast & $5-6$ months & NI & 23 & 28 \\
São Paulo/Southeast & 4 months & M & 19 & 27 \\
São Paulo/Southeast & NI & M/F & 36 & 37 \\
\hline
\end{tabular}

NI - Not informed; M - Male; F - Female 


\section{Macrothink

Individual weighing of the animals and collection of feces for evaluation of FEC were carried out on days zero (treatment) and on weaning days (approximately D120).

\subsection{Statistical Analysis}

Data were analyzed considering the initial weight of the animals as a covariate and the random effects of genetic group, month of birth, and management lot. The SAS University PROC GLIMMIX (SAS Institute Inc., Cary, CA) procedure was used. A significance level of $5 \%$ was considered.

The results of FEC counts (log-transformed), weight, and weight gain were subjected to factorial analysis of variance (two-way ANOVA) and Sidak's multiple comparisons test, to verify differences between groups at the significance level of 5\% using GraphPadPrismversion 6.0 for Windows (GraphPad Software, San Diego, California, USA, www.graphpad.com).

\section{Results}

\subsection{First Stage}

The efficacy of $10 \%$ MOX evaluated in the $38^{\text {th }}$ DPT through FECRT in batches 21 and LA was $98.78 \%$ and $98.21 \%$, respectively, with an average efficacy of $98.49 \%$ (Table 2).

Table 2. Test of reduction in the FEC of calves treated with $10 \%$ MOX before weaning, kept in pickets 21 and LA

\begin{tabular}{lll}
\hline Batch 21 & & \\
\hline & pre-FEC & post-FEC \\
Treated $(\mathrm{n}=11)$ & 78.3 & 2.3 \\
control $(\mathrm{n}=13)$ & 100.0 & 186.5 \\
& Efficacy & $\mathbf{9 8 . 7 8 \%}$ \\
& IC95\% & $95-100 \%$ \\
\hline Batch LA & & \\
\hline & pre-FEC & post-FEC \\
Treated $(\mathrm{n}=25)$ & 304.3 & 4.0 \\
control $(\mathrm{n}=24)$ & 259.8 & 224.0 \\
& Efficacy & $\mathbf{9 8 . 2 1 \%}$ \\
& IC95\% & $93-100 \%$
\end{tabular}

FEC counts were influenced by time and treatment factors. In both groups, there was a significant reduction in the means of FEC in calves between day zero (3-5 months of age) 


\section{Macrothink}

and the time of weaning ( 8 months of age) (Figure 1 and Table 3).

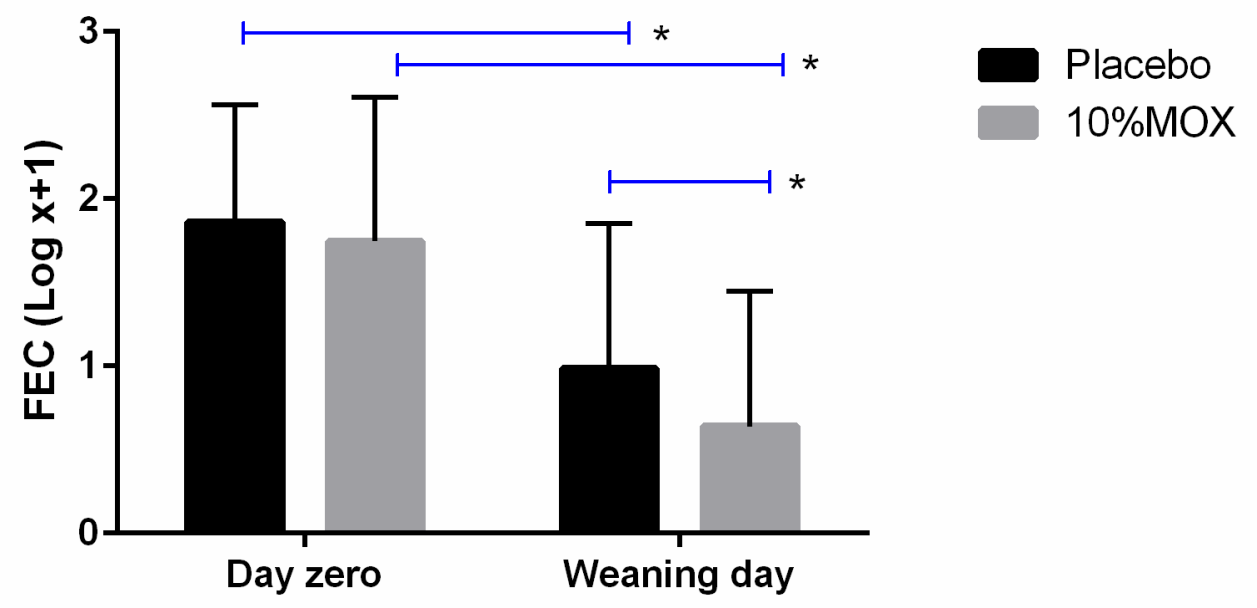

Figure 1. Mean of log-transformed FEC values of calves treated before weaning with $10 \%$ MOX and control group. *statistical difference $(P<0.05)$ by Sidak's multiple comparison test

In addition to the reduction in mean FEC at weaning, in the group of calves treated with $10 \% \mathrm{MOX}$, there was a higher percentage of animals with negative stool analysis $(56.8 \%)$ than in untreated calves $(36 \%)$ (Table 3$)$.

Table 3. Number of animals with negative stool analysis at 3-5 months of age (day zero) and on the day of weaning

\begin{tabular}{lll}
\hline \multirow{2}{*}{ Group } & \multicolumn{2}{c}{ Animals with FEC $=0 /$ total animals } \\
\cline { 2 - 3 } & Treatment day & Weaning day \\
\hline Treated & $15 / 102$ & $58 / 102$ \\
& $14.7 \%$ & $56.8 \%$ \\
\hline Placebo & $10 / 100$ & $36 / 100$ \\
& $10.0 \%$ & $36.0 \%$ \\
\hline
\end{tabular}

In pooled stool cultures of animals in the placebo group on D0, there was a predominance of the genus Cooperia spp, followed by Haemonchus spp. and Oesophagostumum spp. In the control group on the weaning day and in the group treated on D0 and on the weaning day, there was a predominance of the genus Haemonchus spp., followed by Cooperia spp. and Oesophagostomum spp. No larvae of the genus Trichostrongylus spp. were observed in any of the groups, at any time during the study (Figure 2). 

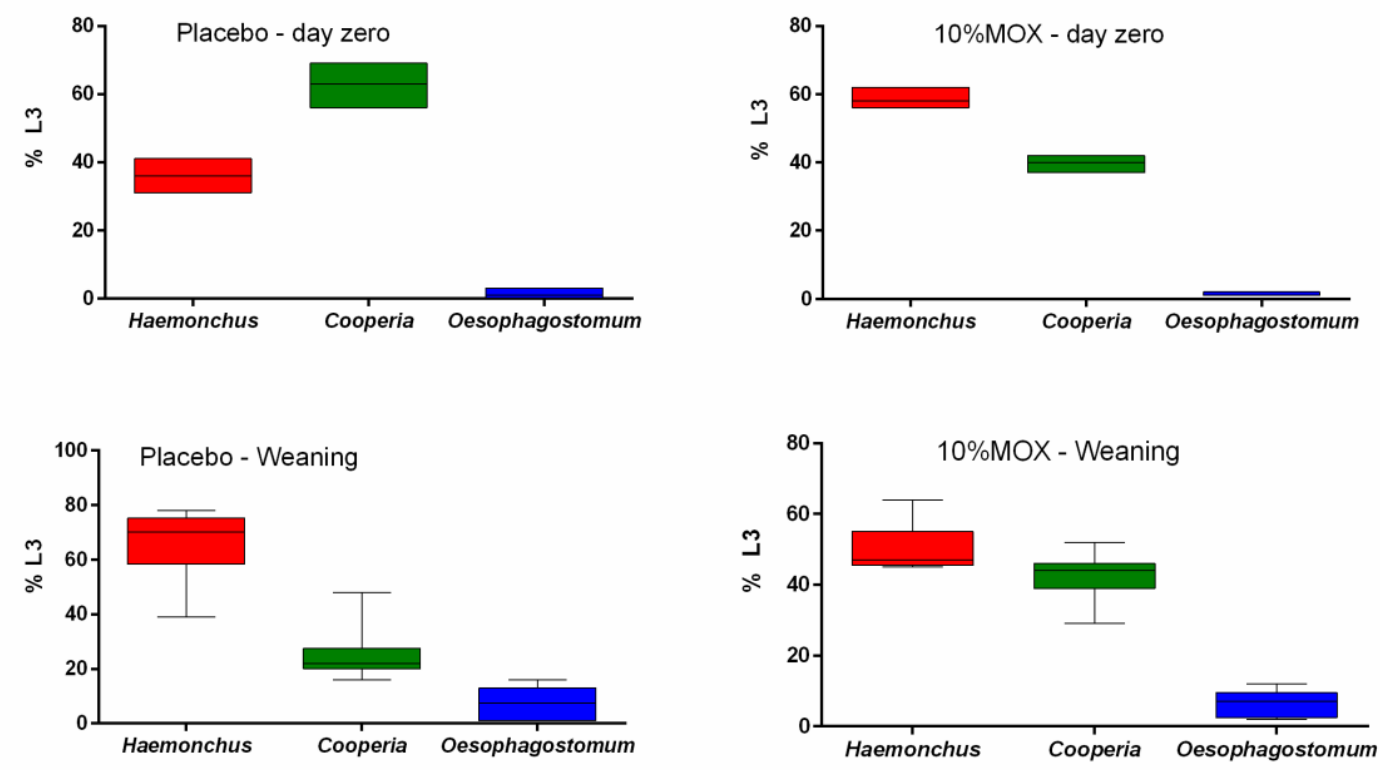

Figure 2. Boxplot, with quartiles $\left(1^{\text {st }}, 2^{\text {nd }}, 3^{\text {rd }}\right.$, and $\left.4^{\text {th }}\right)$ and medians, of the percentage of larvae of each genus recovered in fecal cultures

The effect of the treatment of beef calves at 3-5 months on weight at weaning was significant $(P<0.05)$ and resulted in a difference of $9.4 \mathrm{~kg}$ between the treated group and the placebo group (Table 4 and Figure 3). Treated animals showed an increase in daily gain of 82 grams compared to the control group (Table 4 and Figure 4).

Table 4. Least squares means and standard errors of the means of the weaning weight, mean daily gain, and initial and weaning FEC of calves treated with $10 \%$ MOX before weaning and control group

\begin{tabular}{llcc}
\hline Variable & Control & $10 \%$ MOX & $P$-Value \\
\hline Zero day weight $(\mathrm{kg})$ & $134 \pm 23.7$ & $134 \pm 23.8$ & 0.943 \\
Weaning weight $(\mathrm{kg})$ & $203.5 \pm 21.1$ & $212.9 \pm 21.1$ & $<0.001$ \\
Average daily gain $(\mathrm{kg} / \mathrm{d})$ & $0.515 \pm 0.091$ & $0.597 \pm 0.091$ & $<0.001$ \\
zero day FEC & $133 \pm 81.9$ & $130 \pm 81.6$ & 0.892 \\
weaning FEC & $33.7 \pm 4.32$ & $18.7 \pm 4.21$ & $<0.001$ \\
\hline
\end{tabular}




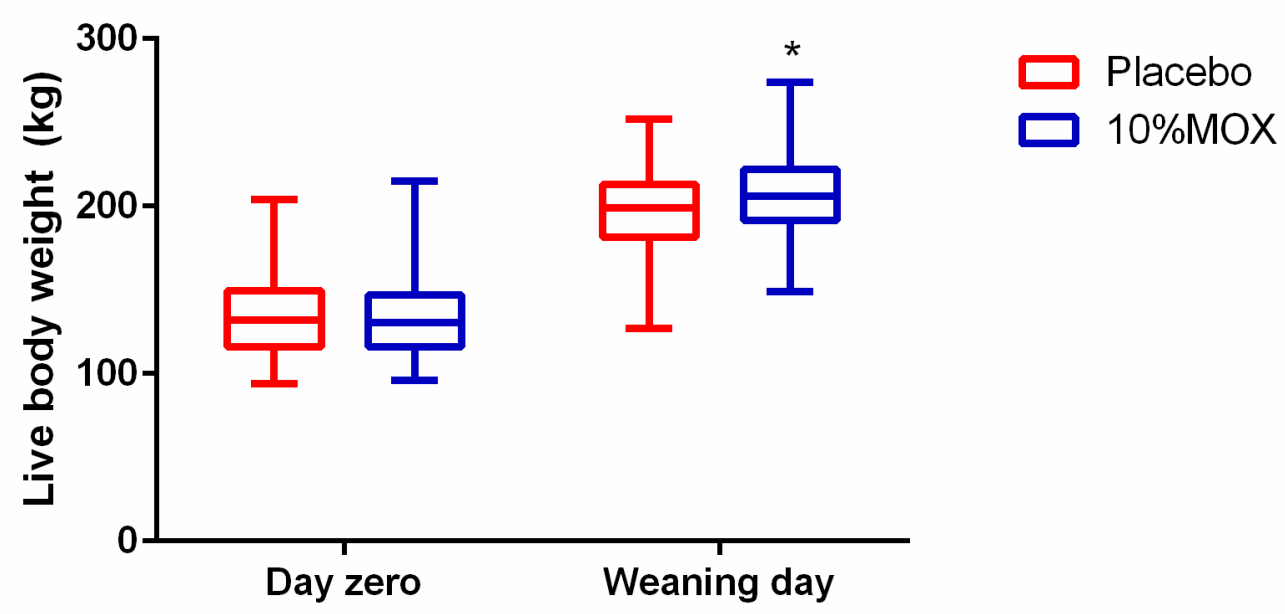

Figure 3. Boxplot, with quartiles $\left(1^{\text {st }}, 2^{\text {nd }}, 3^{\text {rd }}\right.$, and $\left.4^{\text {th }}\right)$ and medians, of the final live weight of calves treated with $10 \% \mathrm{MOX}$ before weaning and placebo group. *statistical difference by

Sidak's multiple comparisons test

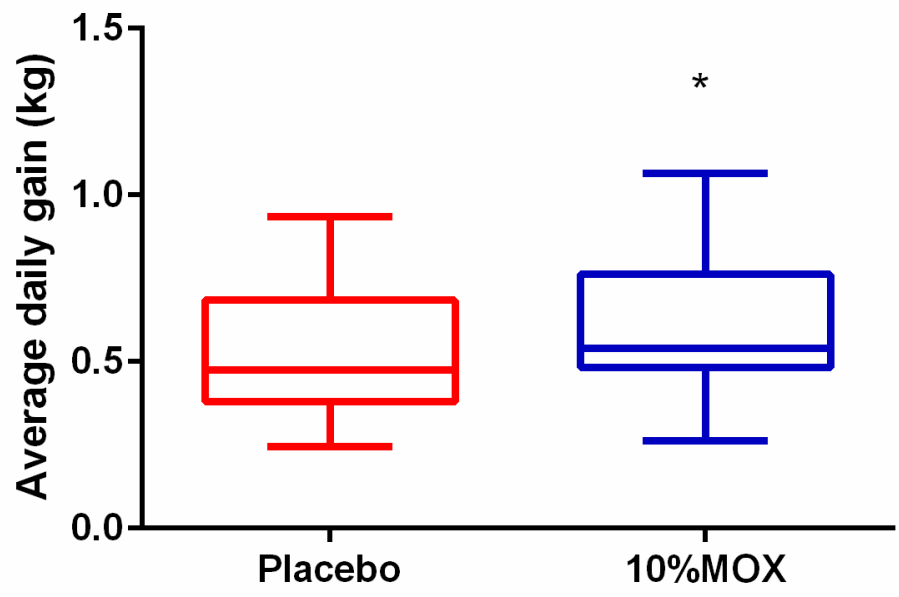

Figure 4. Boxplot, with quartiles $\left(1^{\text {st }}, 2^{\text {nd }}, 3^{\text {rd }}\right.$, and $\left.4^{\text {th }}\right)$ and medians, of the final average daily gain of calves treated with $10 \%$ MOX before weaning and placebo group. *statistical difference by Sidak's multiple comparisons test

\subsection{Second Stage}

In the other 10 clinical studies carried out in the second stage, the calves treated with $10 \%$ MOX showed an increase in $6.1 \mathrm{~kg}(P<0.001)$ in live weight at weaning compared to the control group. Mean FEC counts at weaning in calves treated with $10 \% \mathrm{MOX}$ were lower $(P<0.05)$ than in untreated calves (Table 5). In these clinical studies, it was not possible to perform FECRT until the $38^{\text {th }}$ DPT. 
Table 5. Means of FEC and weight on the day of treatment, at 4-6 months of age, and on the weaning day (D120) in beef calves in 10 clinical studies

\begin{tabular}{lcc}
\hline \multicolumn{1}{l}{ Variable } & Moxidectin 10\% & Placebo \\
\hline Initial live weight $(\mathrm{kg})$ & $145.73 \pm 10.44^{\mathrm{a}}$ & $146.10 \pm 10.45^{\mathrm{a}}$ \\
Final live weight $(\mathrm{kg})$ & $221.90 \pm 7.28^{\mathrm{a}}$ & $217.09 \pm 7.29^{\mathrm{b}}$ \\
Average weight gain (kg/animal) & $75.75 \pm 0.82^{\mathrm{a}}$ & $69.64 \pm 0.86^{\mathrm{b}}$ \\
& & $331.29 \pm 102.51^{\mathrm{a}}$ \\
Initial FEC (eggs/g) & $287.48 \pm 101.54^{\mathrm{a}}$ & \\
Final FEC (eggs/g) & $244.72 \pm 122.23^{\mathrm{a}}$ & $356.48 \pm 123.55^{\mathrm{b}}$ \\
\hline
\end{tabular}

\section{Discussion}

The efficacy percentage found in this study, with an average of $98.49 \%$, shows that the population of gastrointestinal nematodes parasitizing the animals was susceptible to moxidectin, according to the criteria defined by Coles et al. (2006). This result is similar to that reported in Brazil and other countries, where moxidectin remains effective (Soutello et al., 2007; Almeida et al., 2013, Fazzio et al., 2014).

In both stages of the study, treated and untreated animals were kept in the same area, along with their dams and untreated calves, which, according to Reinemeyer (1992), can lead to an underestimation of the effect of the treatment on the weight gain of the treated animals, because they were exposed to the same level of infection. However, this may not be an experimental error; in a study carried out by Heckler et al. (2016) in the state of Mato Grosso do Sul, Brazil, rearing animals were evaluated and the treated and control groups were allocated to different pastures, and there was no difference between the count of larvae in the pastures in the groups, leading to the conclusion that there was no difference in the potential of infection in treated and control animals.

In the current study, the decrease in FEC observed in both groups (treated and control) in the first stage is different from that described for this category in beef calves in the Brazilian cerrado region (Catto et al., 2005). At weaning, an increase in the susceptibility of calves to verminosis is expected, a result that was observed in the second stage, when there was an increase in the FEC of animals belonging to the control group. However, higher FEC means in the preweaning category were also found by Martins (2018) and reinforce the relevance of anthelmintic treatment in this animal category.

Another factor that influenced the FEC counts was the anthelmintic treatment with $10 \% \mathrm{MOX}$ 
in calves aged 3-5 months, with a significant reduction $(P<0.05)$ compared to the control group; this difference was observed in both stages of this study. Similar results have been reported in calves treated between 3 and 6 months with long-acting ivermectin, showing significantly lower mean FEC 84-120 days later, when compared to the control group (Catto et al., 2005; Rehbein et al., 2016).

Neves (2017) described an increase in the weight gain of animals treated during the preweaning phase, when compared to untreated animals kept under the same rearing system; however, in this study, treatments were performed every 28 days, which has little commercial applicability because it increases the expense of anthelmintics and considerably increases the burden of animal handling. On the other hand, the present study showed similar results, with the use of only one treatment, at 3-5 months of age for calves, using a long-acting anthelmintic; this protocol would facilitate animal handling and use in the field and aim to wean heavier calves.

Treatment with 10\%MOX did not affect the percentage distribution of the GIN genera found in the animals of the first stage of the study, a desirable result, as it indicates that resistance selection pressure has not occurred or favored any genus. This result is different from that found by Condi et al. (2009), who reported a proportional increase in L3s of Oesophagostomum spp. in the stool cultures of calves treated with moxidectin.

In the current study, animals treated with $10 \% \mathrm{MOX}$ in both stages showed greater weight gain and a significantly higher average daily gain than the control group. This result supports what was described by Catto et al. (2005), who observed greater weight gain in calves treated with long-acting ivermectin, when compared to animals that received $1 \%$ ivermectin and also animals that did not receive treatment. The effect of anthelmintic treatment on the weight of calves at weaning, even if it is only $6.1 \mathrm{~kg}$ (second stage) or $9.4 \mathrm{~kg}$ (first stage), may not have the consequence of shortening the production cycle in later stages of rearing and finishing, but it certainly results in a greater economic return for the breeding farms, for which the price of weaned calves is based on live weight.

\section{Conclusion}

The study showed effective control of gastrointestinal verminosis and an improvement in the productive performance of calves treated in the preweaning phase, therefore indicating the use of the drug in a single application in animals aged 3-5 months.

\section{Acknowledgments}

This study was financed in part by the Coordenação de Aperfeiçoamento de Pessoal de Nível Superior - Brasil (CAPES) - Finance Code 001 and by the Universidade Federal de Mato Grosso do Sul - UFMS/MEC - Brazil.

\section{References}

Almeida, G. D., Feliz, D. C., Heckler, R. P., Borges, D. G. L., Onizuka, M. K. V., Tavares, L. 
E. R., Paiva, F., \& Borges, F. A. (2013) Ivermectin and moxidectin resistance characterization by larval migration inhibition test in field isolates of Cooperia spp. in beef cattle, Mato Grosso do Sul, Brazil. Veterinary Parasitology, 191, 59-65. http://doi.org/10.1016/j.vetpar.2012.08.012

Bianchin, I., Honer, M. R., Nunes, S. G., Nascimento, Y. A., Curvo, J. B. E., \& Costa, F. P. (1996). Epidemiologia dos nematódeos gastrintestinais em bovinos de corte noscerrados e o controle estratégico no Brasil Campo Grande-MS, Brasil. Techn. Circular, 24, 05-69.

Bianchin, I, Honer, M. R., \& Curvo, J. B. E. (1987). Produção de ovos de nematódeos gastrintestinais em vacas nelore, durante o período periparto. Pesquisa Agropecuária Brasileira, 22(11/12), 1239-1243.

Borges, F. A., Borges, D. G. L., Heckler, R. P., Neves, J. P. L., Lopes, F. G., \& Onizuka, M. K. V. (2015). Multispecies resistance of cattle gastrointestinal nematodes to long-acting avermectin formulations in Mato Grosso do Sul. Veterinary Parasitology, 212, 299-302. http://doi.org/10.1016/j.vetpar.2015.06.015

Canton, C, Ceballos, L, Domínguez, M. P., Fiel, C., Lirón, J. P., Moreno, L, Canton, L., Bernat, G., Lanusse, C., \& Alvarez, L. I. (2020). Impact on beef cattle productivity of infection with anthelmintic-resistant nematodes. New Zealand Veterinary Journal, 68, 187-192. https://doi.org/10.1080/00480169.2019.1698999

Catto, J. B., Bianchin, I., \& Torres, R. A. A. (2005). Efeitos da everminação e de bezerros lactentes em sistema de produção de bovinos de corte na região do Cerrado. Pesquisa Veterinária Brasileira, 23(3), 188-194. https://doi.org/10.1590/S0100-736X2005000300010

Coles, G. C., Bauer, C., Borgsteede, F. H. M., Geerts, S., Klei, T. R., Taylor, M. A., \& Waller, P. J. (1992). World Association for the Advancement of Veterinary Parasitology (W.A.A.V.P.) methods for the detection of anthelmintic resistance in nematodes of veterinary importance. Veterinary Parasitology, 44, 35-44. https://doi.org/10.1016/0304-4017(92)90141-U

Coles, G. C., Jackson, F., Pomroy, W. E., Prichard, R. K., Von Samson-Himmelstjerna, G., Silvestre, A., Taylor, M. A., \& Vercruysse, J. (2006) The detection of anthelmintic resistance in nematodes of veterinary importance. Veterinary Parasitology, 136, 167-185. https://doi.org/10.1016/j.vetpar.2005.11.019

Conde, M., Heckler, R. P., Borges, D. G., Onselen, V. J., Brumatti, R. C., \& Borges, F. (2019). Economic analysis of strategic control program $(5,8,11)$ for gastrointestinal nematodes in grazing beef cattle during the growing phase in Central Brazil. Semina: Ciencias Agrarias, 40(5), 2309-2318. https://doi.org/10.5433/1679-0359.2019v40n5Sup11p2309

Condi, G. K., Soutello, R. G. V., \& Amarante, A. F. T. (2009). Moxidectin-resistant nematodes in cattle in Brazil. Veterinary Parasitology, 161, 213-217. https://doi.org/10.1016/j.vetpar.2009.01.031

Fazzio, L. E., Sánchez, R. O., Streitenberger, N., Galvan, W. R., Giudici, C. J., \& Gimeno, E. J. (2014). The effect of anthelmintic resistance on the productivity in feedlot cattle. 
Veterinary Parasitology, 206, 240-245. https://doi.org/10.1016/j.vetpar.2018.12.016

Gordon, H. M., \& Whitlock, H. V. (1939). A new technique for counting nematode eggs in sheep faeces. Journal of the Council for Scientific and Industrial Research, 12, 50-52.

Grisi, L., Leite, R. C., Martins, J. R. S., Barros, A. T. M., Andreotti, R., Cançado, P. H. D., León, A. A. P., Pereira, J. B., \& Villela, H. S. Reassessment of the potential economic impact of cattle parasites in Brazil. Brazilian Journal of Veterinary Parasitology, 23(2), 150-156. http://doi.org/10.1590/S1984-29612014042

Heckler, R. P., Borges, D. G. L., Vieira, M. C., Conde, M. H., Green, M., Amorim, M. L., Echeverria, J. T., Oliveira, T. L., Moro, E., Van Onselen, V. J., \& Borges F.A. (2016). New approach for the strategic control of gastrointestinal nematode in grazed beef cattle during the growing phase in central Brazil. Veterinary Parasitology, 221, 123-129. http://doi.org/10.1016/j.vetpar.2016.03.010

Keith, R. K. (1953). The differentiation on the infective larvae of common nematodes parasites of cattle. Australian Journal of Zoology, 1, 223-235. https://doi.org/10.1071/ZO9530223

Knox. M. R., Besier, R. B., Le Jambre, L.F., Kaplan, R. M., Torres-Acosta, J. F. J, Miller, J., $\&$ Sutherland, I. (2012). Novel approaches for the control of helminth parasites of livestock VI: Summary of discussions and conclusions. Veterinary Parasitology, 186, 143-149. https://doi.org/10.1016/j.vetpar.2011.11.054

Martins, M. S. S. (2018). Contagem de ovos nas fezes versus resposta imune: relação ou ilusão? [Dissertação de mestrado, Universidade Federal de Mato Grosso do Sul]. https://posgraduacao.ufms.br/portal/trabalho-arquivos/download/5631

Neves, J. H. (2017). Effect of anthelmintic treatment on the ponderal development of Nelore, Simmental and crossbred cattle between two breeds. [Tese doutorado, Universidade Estadual Paulista]. https://repositorio.unesp.br/handle/11449/151533

Rehbein, S., Knaus, M., Visser, M., Rauh, R., \& Yoon, S. (2016). Control of parasitic infection with ivermectin long-acting injection (IVOMEC® GOLD) and production benefit in first-season grazing cattle facing a high-level larval challenge in Germany. Parasitology Research, 115, 4639-4648. https://doi.org/10.1007/s00436-016-5256-2

Reinemeyer, C. R. (1992). The effects of anthelmintic treatment of beef cows on parasitologic and performance parameters. Compendium on Continuing Education for the Practising Veterinarian, 14(5), 678-686.

Roberts, F. H. S., \& O'Sullivan, P. J. (1950). Methods for egg counts and larval cultures for strongyles infecting tract of cattle. Australian Journal of Agricultural Research, 1, 99-102.

Soutello, R. G. V., Seno, M. C. Z., \& Amarante, A. F. T. (2007). Anthelmintic resistance incattle nematodes in northwestern São Paulo State Brazil. Veterinary Parasitology, 148, 360-364. https://doi.org/10.1016/j.vetpar.2007.06.023 


\section{Macrothink}

Journal of Agricultural Studies

ISSN 2166-0379 2021, Vol. 9, No. 4

Suarez, V. H., Martínez1, G. M., Micheloud, J. F., \& Viñabal, A. E. (2017). Epidemiology and effect of gastrointestinal nematodes on beef cattle from tropical Argentina. Tropical Animal Health and Production, 50, 801-806. https://doi.org/10.1007/s11250-017-1498-y

Ueno, H., \& Gonçalves, P. C. (1998) Manual para diagnóstico das helmintoses de ruminantes (4.ed.). JICA.

Van der Voort, M., Charlier, J., Lauwers, L., Vercruysse, J., Van Huylenbroeck, G., \& Van Meensel, J. (2013). Conceptual framework for analyzing farm-specific economic effects of helminth infections in ruminants and control strategies. Preventive Veterinary Medicine, 109, 228-235. https://doi.org/10.1016/j.prevetmed.2012.10.017

Walker, R. S., Miller, J. E., Monlezun, C. J., LaMay, D., Navarre, C., \& Ensley, D. (2013). Gastrointestinal nematode infection and performance of weaned stocker calves in response to anthelmintic control strategies. Veterinary Parasitology, 197, 152-159. https://doi.org/10.1016/j.vetpar.2013.07.011

\section{Copyright Disclaimer}

Copyright for this article is retained by the author(s), with first publication rights granted to the journal.

This is an open-access article distributed under the terms and conditions of the Creative Commons Attribution license (http://creativecommons.org/licenses/by/4.0/). 